\title{
Removal of Polyvinyl Alcohol in Aqueous Solutions Using an Innovative Paired Photoelectrochemical Oxidative System in a Divided Electrochemical Cell
}

\author{
Kai-Yu Huang, ${ }^{1}$ Chih-Ta Wang, ${ }^{2}$ Wei-Lung Chou, ${ }^{3}$ and Chi-Min Shu' \\ ${ }^{1}$ Department of Safety, Health and Environmental Engineering, National Yunlin University of Science and Technology, \\ Yunlin 64002, Taiwan \\ ${ }^{2}$ Department of Safety, Health and Environmental Engineering, Chung Hwa University of Medical Technology, Tainan 717, Taiwan \\ ${ }^{3}$ Department of Safety, Health and Environmental Engineering, Hungkuang University, Sha-Lu, Taichung 433, Taiwan
}

Correspondence should be addressed to Wei-Lung Chou; wlchou@sunrise.hk.edu.tw

Received 23 July 2014; Accepted 2 October 2014

Academic Editor: Bashir Ahmmad

Copyright (C) 2015 Kai-Yu Huang et al. This is an open access article distributed under the Creative Commons Attribution License, which permits unrestricted use, distribution, and reproduction in any medium, provided the original work is properly cited.

\begin{abstract}
This study evaluates the performance of an innovative paired photoelectrochemical oxidative system fabricated in our laboratory to determine the removal efficiency of polyvinyl alcohol (PVA) in aqueous solutions. An innovative paired photoelectrochemical oxidative system employed metal redox mediators with high redox potential for anodic oxidation (MEO process) and UV assisted photoelectrochemical oxidation (PEO process) for cathodic oxidation in a divided electrochemical cell. Several parameters were investigated to characterize the removal efficiency of PVA, such as the current density, initial Ce(III) concentration, nitric acid concentration, oxygen flow rate, and UV irradiation intensity. The effects of these parameters on the specific energy consumption were also investigated. Additionally, the conversion yield of $\mathrm{Ce}(\mathrm{IV})$ concentration and the electrogeneration of $\mathrm{H}_{2} \mathrm{O}_{2}$ were calculated in this study. The optimum current density, initial Ce(III) concentration, nitric acid concentration, oxygen flow rate, and UV irradiation intensity were found to be $3 \mathrm{~mA} \mathrm{~cm}{ }^{-2}, 0.01 \mathrm{M}, 0.3 \mathrm{M}, 500 \mathrm{~cm}^{3} \mathrm{~min}^{-1}$, and $1.2 \mathrm{~mW} \mathrm{~cm}^{-2}$, respectively. The synergistic effect of combination process of MEO and PEO would be as a promising alternative for the removal efficiency of PVA.
\end{abstract}

\section{Introduction}

Due to rapid development of industrial, polymers are increasingly used in various industrial products, polyvinyl alcohol especially. Polyvinyl alcohol (PVA) is widely used as warp sizes for cotton-synthetic blends in the textile industry and the molecular structure of $\left[-\mathrm{CH}_{2}-\mathrm{CH}(\mathrm{OH})\right]_{n}$ makes it possess of well water solubility [1]. The global production of PVA is almost over 650,000 tons/year. It is also used for polarizing film light in liquid crystal displays (LCDs) [2]. However, discharging of a large quantity of PVA influences both human health and natural environment [3] and leads to high chemical oxygen demand (COD) in the industrial effluents. It is difficult to convert wastewaters containing PVA to generate harmless end-products like water and carbon dioxide. Therefore, PVA adversely can affect the ecosystem and accumulates in the human body through the food chain
[4]. Conventional biological technologies do not provide an efficacious treatment of wastewaters containing PVA, because most microorganisms degradation ability for PVA is extremely specific and restricted [5]. An effective method for the treatment of wastewaters containing PVA has to be developed. For the treatment of PVA wastewater, a number of chemical processes have been investigated, including adsorption $[1,6,7]$, photocatalysis degradation process [8$11]$, chemical oxidation $[12,13]$, electrocoagulation [14], and electro-Fenton [15]. However, to date, there is little research on the development of a paired photoelectrochemical oxidative system treatment for the removal of PVA.

In recent years, electrochemical treatment technology has been applied in various ways to clean the environment such as anodic oxidation, cathodic reduction, and electro-Fenton process [16-18]. Advanced oxidation processes (AOPs) and mediated electrochemical oxidation (MEO) are new 


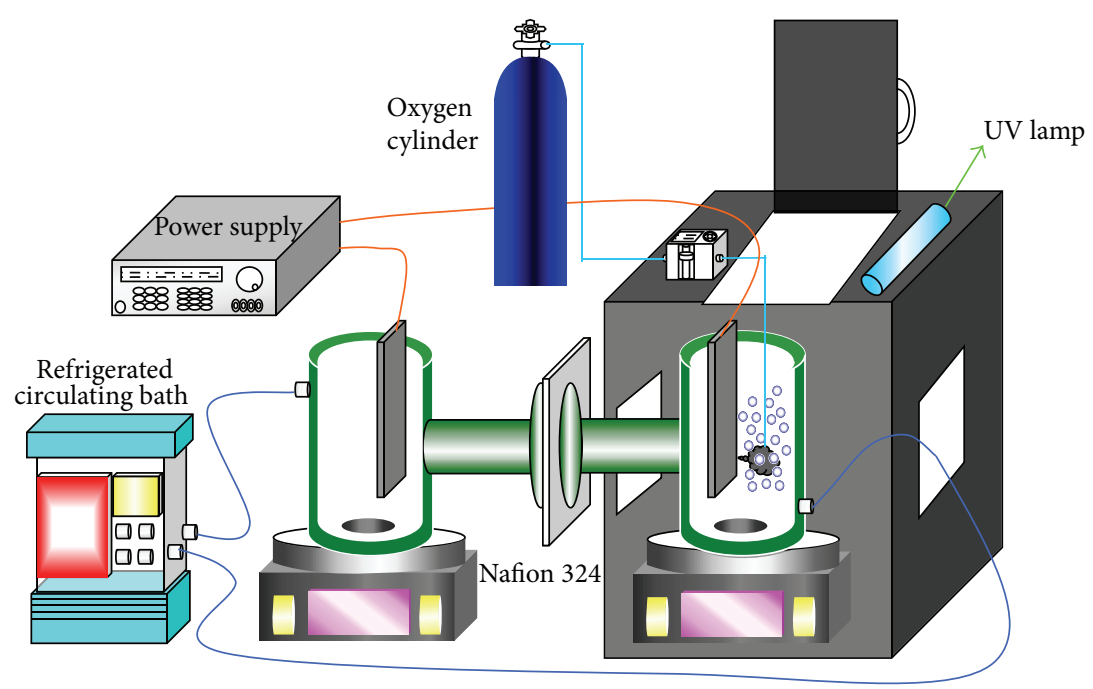

FIGURE 1: Schematic diagram of the paired photoelectrochemical oxidative equipment.

technology for the treatment of industrial wastewater containing organic compounds. Both promising technologies can mineralize the organics into nontoxic carbon dioxide and water $[19,20]$. AOPs are based on generation strong oxidant of hydroxyl radicals that can nonselectively degrade organic contaminants rapidly [21]. Among all AOPs methods, hydrogen peroxide often has been used as a powerful oxidant to generate $\mathrm{OH}^{\bullet}$ for oxidizing wastewater of organic compounds [9, 22-24]. A combination UV irradiation and $\mathrm{H}_{2} \mathrm{O}_{2}$ process can effectively increase the oxidative power of hydrogen peroxide due to the production of hydroxyl free radicals, as shown in the reaction $\mathrm{H}_{2} \mathrm{O}_{2}+\mathrm{UV} \rightarrow$ $2 \mathrm{OH}^{\circ}$. The $\mathrm{UV} / \mathrm{H}_{2} \mathrm{O}_{2}$ process also has been proven to be efficient in degrading organic compounds $[25,26]$. Therefore, the hydroxyl free radicals were produced by photoelectrochemical oxidation (PEO) process in the cathodic compartment.

MEO technique presents several advantages: easy operations, simple equipment, less sludge production, the oxidant can conveniently be reused, and avoided production of secondary wastes. In the MEO process, the mediator ion is a transition metal, such as cobalt, cerium, and silver [27-30]. These mediators can be oxidized from lower oxidation state to higher oxidation state to mineralize organic complexes. Among these mediators, cerium (IV) has good oxidizing property because of its higher redox potential $\left(E^{0}=1.62 \mathrm{~V}\right)$. However, in the traditional electrochemical anodic oxidation system, the cathodic compartment usually only reduces the water and generate hydrogen gas. Thus, the removal efficiency of organic substance cannot be effectively increased to result in energy waste. In order to improve the overall current efficiency, we will combine the MEO process of the anodic compartment with $\mathrm{PEO}$ reaction to generate hydroxyl free radicals at the cathodic compartment to form a paired photoelectrochemical oxidative system. To the best of our knowledge, very little work has been reported in the literature to date on PVA removal by an innovative paired photoelectrochemical oxidative system.
In the present study, parameters such as current density, initial $\mathrm{Ce}$ (III) concentration, nitric acid concentration, oxygen flow rate, and UV irradiation intensity were investigated in terms of the PVA removal efficiency. A technically effective process must be economically feasible with regard to its specific energy consumption (SEC) and practically applicable to environmental problems. The effects of the main operational parameters (current density, initial Ce(III) concentration, nitric acid concentration, oxygen flow rate, and UV irradiation) on SEC under the optimum conditions were evaluated. The yield of the $\mathrm{Ce}(\mathrm{IV})$ concentration and the electrogeneration of $\mathrm{H}_{2} \mathrm{O}_{2}$ on the different operational parameters by $\mathrm{MEO}$ process of the anodic compartment and PEO process of the cathodic compartment were also investigated in this study.

\section{Experimental}

2.1. Chemicals and Apparatus. Cerium(III) nitrate hexahydrate was obtained from Alfa Aesar (USA). Polyvinyl alcohol (PVA, molecular weight in the range of 13,000 to 23,000 $\mathrm{g} \mathrm{mol}^{-1}$ ) was obtained from Sigma-Aldrich (USA) with a hydrolysis degree ranging from 98 to $99 \% . \mathrm{Na}_{2} \mathrm{SO}_{4}$ was purchased from Merck (Germany), and $\mathrm{HNO}_{3}$ (65\%) was obtained from Scharlau (Spain). Titanium(IV) sulfate (24\%) was purchased from SHOWA (Japan). Boric acid (99.5\%) was supplied by Merck, and potassium iodide (99.5\%) and iodine (99.5\%) were obtained from Union Chemical Work Ltd. (Taiwan) and Toyobo Co. Ltd. (Japan), respectively. All chemicals were analytical grade reagents and were prepared by dilution with deionized water to the desired concentrations. The activated carbon fiber (ACF), PAN-based rigid composite carbon felt series, was obtained from Taiwan carbon Technology Co. Ltd. (Taiwan).

Figure 1 is a schematic diagram of the paired photoelectrochemical system and the electrode assembly used in this work. The anodic and cathodic electrolytic cell was $0.5 \mathrm{~L}$ glass reactor equipped with a water jacket and a magnetic stirrer. 
The electrolytic cell consisted of an anode and a cathode separated by a Nafion 324 membrane. The temperature of the electrolytic cell was controlled by continuously circulating water jacket from a refrigerated circulating bath (Model BL720, Taiwan). A magnetic stirrer bar (Suntex SH-301, Taiwan) was spun at the center of the bottom of the reactor. The platinum anode $\left(6 \mathrm{~cm}^{2}\right)$ and ACF cathode $\left(20 \mathrm{~cm}^{2}\right)$ were immersed in the PVA aqueous solution at a depth of $5 \mathrm{~cm}$. In the following, all experiments were conducted using a $\mathrm{Pt} / \mathrm{ACF}$ electrode combination. The oxygen gas from an oxygen cylinder was dispersed at the bottom of the cathode. The electric current was supplied by a DC power supply (PSM-6003, Taichung, Taiwan). A UV lamp ( $8 \mathrm{~W}, \mathrm{UV}-\mathrm{C}, \lambda_{\max }$ $=254 \mathrm{~nm}$, manufactured by Sankyo denski, Japan) was used as a radiation source and placed above a cathodic reactor. The UV-light intensity was measured by a Digital Ultraviolet Radiometer (Rixen Technology, Taiwan).

2.2. Methods and Analysis. The experiments were conducted in a divided glass vessel. Before each experiment, the electrodes were cleaned with deionized water. During each test run, two circular containers with $0.4 \mathrm{~L}$ of synthetic wastewater containing polyvinyl alcohol were as the reactor. Then, the magnetic stirrer was turned on and set at $300 \mathrm{rpm}$; this stirrer speed was sufficient for good mixing in the electrolytic cell. The ACF felt was saturated with $1000 \mathrm{mg} \mathrm{L}^{-1}$ PVA solution for $24 \mathrm{~h}$ to exclude the adsorption reaction of PVA on the ACF felt. The direct current power source was operated with a constant current density of $1,2,3,4$, and $5 \mathrm{~mA} \mathrm{~cm}^{-2}$. A constant $\mathrm{Ce}(\mathrm{III})$ concentration $(0.001 \mathrm{M}$ to $0.02 \mathrm{M})$ and $\mathrm{HNO}_{3}$ concentration $(0.1 \mathrm{M}$ to $0.5 \mathrm{M})$ were adjusted in the anodic compartment during the experiments. The cathodic compartment was fed with an oxygen gas flow rate of 100 to $900 \mathrm{~cm}^{3} \mathrm{~min}^{-1}$, and the UV light intensity ( 0 to $1.2 \mathrm{~mW} \mathrm{~cm}^{-2}$ ) was controlled by UV lamps during the experiments. The paired photoelectrochemical system treatment run lasted $120 \mathrm{~min}$ in all experiments. Prior to the electrolysis, the oxygen gas was bubbled for $10 \mathrm{~min}$ to saturate the aqueous solution; then, the electric power was turned on, and the paired photoelectrochemical reactions started simultaneously. Samples were drawn out from the reactor at default time intervals and then analyzed.

The $\mathrm{H}_{2} \mathrm{O}_{2}$ concentration was determined using the $\mathrm{Ti}\left(\mathrm{SO}_{4}\right)_{2}$ titration method and spectrophotometric analysis at $\lambda=410 \mathrm{~nm}$ [31]. Ce(IV) concentration was quantitatively determined using ferrous ammonium sulfate dissolved in $0.005 \mathrm{M}$ nitric acid [32]. The amount of $\mathrm{Ce}(\mathrm{IV})$ generated theoretically is dependent on the quantity of applied electricity. According to Faraday's laws of electrolysis, the theoretical production of $\mathrm{Ce}(\mathrm{IV})$ amount $\left(m_{t}\right)$ at electrolysis time $t$ can be calculated as follows [33]:

$$
m_{t}=\frac{M I t}{z F},
$$

where $M$ is molecular weight of Ce; $I$ is the applied current; $z$ is the electrons transferred per Ce(III) ion $(z=1$ in $\left.\mathrm{Ce}(\mathrm{III}) \rightarrow \mathrm{Ce}(\mathrm{IV})+\mathrm{e}^{-}\right)$; and $F$ is the Faraday's constant.
Quantitative determination of PVA concentration in the aqueous solutions was carried out using a $\mathrm{HACH}$ Model DR2800 spectrophotometer (USA) after addition of boric acid and iodine solutions according to the procedure described by Finley [34]. A calibration curve was obtained by plotting the absorbance value at $680 \mathrm{~nm}$ against polyvinyl alcohol concentration. The calculation of the PVA destruction efficiency after the paired photoelectrochemical treatment was performed using the following formula:

$$
\mathrm{RE}(\%)=\frac{C_{0} V_{0}-C_{t} V_{t}}{C_{0} V_{0}} \times 100,
$$

where $C_{0}$ is the initial concentration in $\mathrm{mg} \mathrm{L}^{-1}, C_{t}$ is the concentration value at time $t$ in $\mathrm{mgL}^{-1}, V_{0}$ is the initial volume of the treated wastewater in liters, and $V_{t}$ is the volume of the treated wastewater at time $t$ in liters. All of the samples were evaluated at least fifth to ensure data reproducibility, and an additional measurement was carried out if necessary.

\section{Results and Discussion}

3.1. Effect of Current Density. Current density is an important operating factor that strongly controls the reaction rate in the electrochemical engineering. It determines the electrogeneration of $\mathrm{Ce}(\mathrm{IV})$ from the initial $\mathrm{Ce}(\mathrm{III})$ by the anodic $\mathrm{MEO}$ process and electrogeneration of $\mathrm{H}_{2} \mathrm{O}_{2}$ by the cathodic PEO process in the paired photoelectrochemical oxidative system. The mechanism of the anodic MEO process and the cathodic PEO process removal of PVA may be expressed as follows.

For the anodic process:

$$
\begin{gathered}
\mathrm{Ce}^{3+} \longrightarrow \mathrm{Ce}^{4+}+\mathrm{e}^{-} \\
\mathrm{PVA}+\mathrm{Ce}(\mathrm{IV}) \longrightarrow \text { intermediates } \longrightarrow \mathrm{CO}_{2}+\mathrm{H}_{2} \mathrm{O}
\end{gathered}
$$

For the cathodic process:

$$
\begin{gathered}
\mathrm{H}_{2} \mathrm{O}_{2}+\mathrm{UV} \longrightarrow 2 \mathrm{OH}^{\bullet} \\
\mathrm{PVA}+\mathrm{OH}^{\bullet} \longrightarrow \text { intermediates } \longrightarrow \mathrm{CO}_{2}+\mathrm{H}_{2} \mathrm{O}
\end{gathered}
$$

The effect of the current density on the PVA removal efficiency in the anodic and cathodic compartment was studied at 1, 2, 3, 4, and $5 \mathrm{~mA} \mathrm{~cm}^{-2}$. Figure 2(a) indicated the effect of different current density on the removal efficiency of PVA in the anodic and cathodic compartment. As the current density increased, the PVA removal efficiencies increased. After 120 min of electrolysis, it can be seen from Figure 2(a) that the removal efficiency of PVA in the anodic compartment was $51.2 \%, 62.7 \%, 77.8 \%, 79.3 \%$, and $80.4 \%$ and cathodic compartment was $20.8 \%, 27.7 \%, 29.4 \%, 31.6 \%$, and $32.8 \%$ for the current densities of $1,2,3,4$, and $5 \mathrm{~mA} \mathrm{~cm}^{-2}$, respectively. According to (3), the reduced Ce(III) can be electrooxidized to Ce(IV) in the anodic compartment, as shown in Table 1. Therefore, the Ce(IV) can be reused as the oxidant for the continuous removal of PVA and avoided the generation of secondary waste. In the cathodic compartment, the 


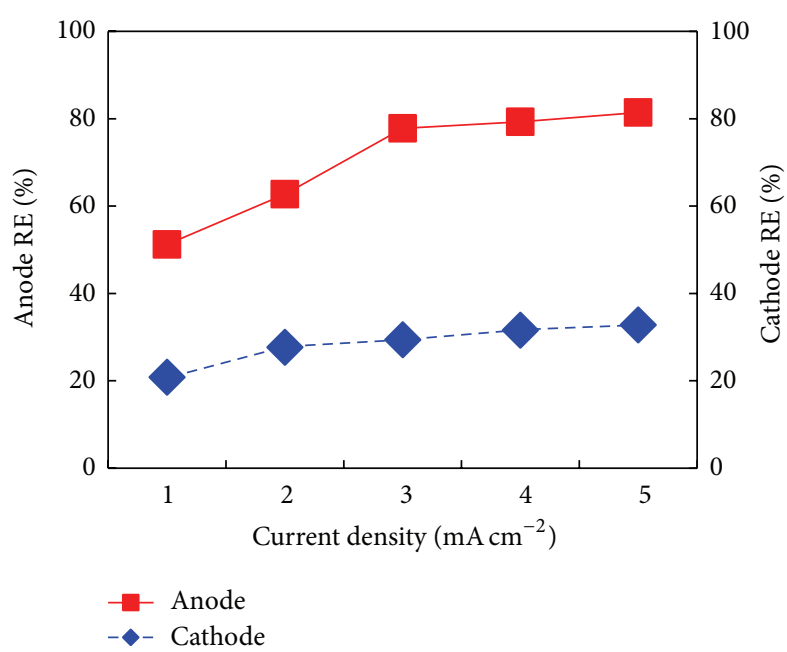

(a)

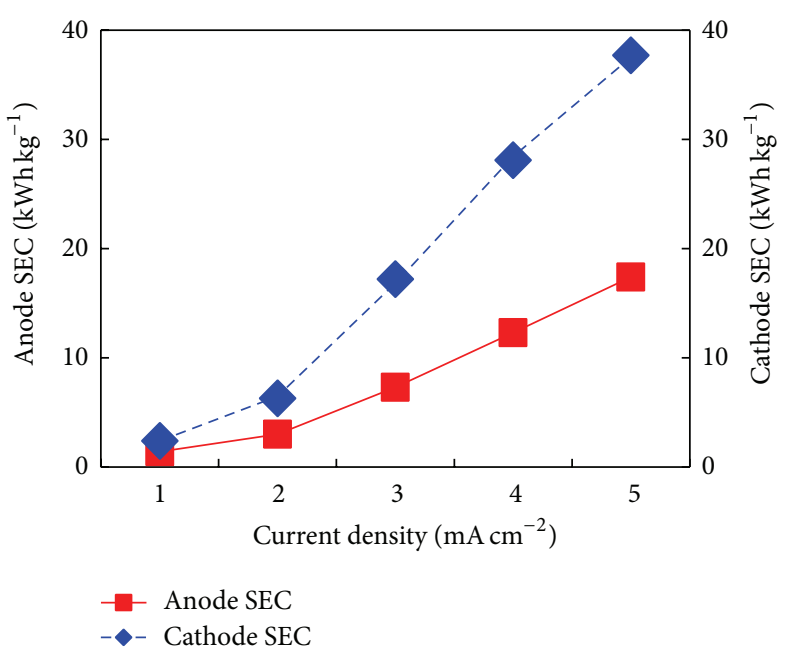

(b)

FIGURE 2: Effect of current density: (a) anodic and cathodic compartment removal efficiency of PVA and (b) SEC of anodic and cathodic compartment removal of PVA (temperature $=323 \mathrm{~K}$, anodic compartment: $\mathrm{PVA}=50 \mathrm{mg} \mathrm{L}^{-1}, \mathrm{Ce}(\mathrm{III})=0.01 \mathrm{M}, \mathrm{HNO}_{3}=0.2 \mathrm{M}$; cathodic compartment: $\mathrm{PVA}=50 \mathrm{mg} \mathrm{L}^{-1}, \mathrm{Na}_{2} \mathrm{SO}_{4}=0.05 \mathrm{M}, \mathrm{pH}=3$, oxygen flow rate $=500 \mathrm{~cm}^{3} \mathrm{~min}^{-1}$, and UV-light intensity $=0.4 \mathrm{~mW} \mathrm{~cm}^{-2}$ ).

TABLE 1: Effect of the current density on the $\mathrm{Ce}(\mathrm{IV})$ and $\mathrm{H}_{2} \mathrm{O}_{2}$ electrogeneration during a paired photoelectrochemical oxidative system.

\begin{tabular}{lcc}
\hline $\begin{array}{l}\text { Current density } \\
\left(\mathrm{mA} \mathrm{cm}^{-2}\right)\end{array}$ & $\begin{array}{c}\text { Yield of } \mathrm{Ce}(\mathrm{IV}) \\
\text { concentration }(\%)\end{array}$ & $\begin{array}{c}\text { Concentration of } \mathrm{H}_{2} \mathrm{O}_{2} \\
\text { generation }\left(\mathrm{mg} \mathrm{L}^{-1}\right)\end{array}$ \\
\hline 1 & 5 & 9 \\
2 & 8.7 & 9.6 \\
3 & 12.3 & 14.5 \\
4 & 13.3 & 16.6 \\
5 & 16 & 20.3 \\
\hline
\end{tabular}

electrogenerated $\mathrm{H}_{2} \mathrm{O}_{2}$ was catalyzed into hydroxyl radicals by UV light, which were very powerful oxidizing species. These hydroxyl radicals can effectively oxidize the PVA. As shown in Table 1 , a significant increase in the $\mathrm{H}_{2} \mathrm{O}_{2}$ yield was observed with increasing current density; thus there was more generation of hydroxyl radicals to oxidize PVA. However, no significant improvement in the PVA removal efficiency was observed while the current density increased from 3 to $5 \mathrm{~mA} \mathrm{~cm}^{-2}$.

In order to obtain the optimum current density when concerning the energy efficiency, the specific energy consumption (SEC) [35] for removing $1 \mathrm{Kg}$ PVA at a specified certain electric current was calculated by the following:

$$
\begin{aligned}
\operatorname{SEC}\left(\mathrm{kWh} \mathrm{kg}^{-1}\right) & =\frac{\int U \times I d t}{\left(C_{0} V_{0}-C_{t} V_{t}\right) \times 3.6} \\
& =\frac{I \int U d t}{\left(C_{0} V_{0}-C_{t} V_{t}\right) \times 3.6},
\end{aligned}
$$

where $U, I, t$ were the applied voltage $(\mathrm{V})$, current $(\mathrm{A})$, and electrolysis time (min), respectively. In addition, $C_{0}\left(\mathrm{mg} \mathrm{L}^{-1}\right)$ is the initial concentration, $C_{t}\left(\mathrm{mg} \mathrm{L}^{-1}\right)$ is the concentration value at time $t, V_{0}(\mathrm{~L})$ is the initial volume of the treated wastewater, and $V_{t}(\mathrm{~L})$ is the volume of the treated wastewater at time $t$. A reasonable removal efficiency and relatively low energy consumption were determined below. Figure 2(b) also shows the SEC values of anodic and cathodic compartment after $120 \mathrm{~min}$ of electrolysis at different current densities. It can be obviously seen that increasing current density had a significant effect on SEC. When the current density varied from 1 to $5 \mathrm{~mA} \mathrm{~cm}^{-2}$, we observed a dramatic increase in the SEC value from $1.4 \mathrm{kWh} \mathrm{kg}^{-1}$ to $17.4 \mathrm{kWh} \mathrm{kg}^{-1}$ in the anodic compartment and $2.4 \mathrm{kWh} \mathrm{kg}^{-1}$ to $37.7 \mathrm{kWh} \mathrm{kg}^{-1}$ in the cathodic compartment for PVA removal. However, as the current density was increased from 3 to $5 \mathrm{~mA} \mathrm{~cm}^{-2}$, the anodic and cathodic PVA removal efficiency increased slightly, whereas the corresponding electric energy consumption increased by almost 2 times. Consequently, when considering both the electric energy consumption and the PVA removal efficiency, $3 \mathrm{~mA} \mathrm{~cm}^{-2}$ offers the best compromise, providing a reasonable PVA removal efficiency and relatively low electrical energy consumption.

\subsection{Removal of PVA in the Anodic Compartment}

3.2.1. Effect of Initial Ce(III) Concentration. In this study, the effect of initial Ce(III) concentration on the PVA removal efficiency was studied at $0.001,0.0025,0.005,0.01$, and $0.02 \mathrm{M}$, as shown in Figure 3(a). After $120 \mathrm{~min}$ of electrolysis, we observed that the PVA removal efficiencies reached $38.6 \%$, $51 \%, 56 \%, 77.8 \%$, and $80.1 \%$ for initial Ce(III) concentrations of $0.001,0.0025,0.005,0.01$, and $0.02 \mathrm{M}$, respectively. This phenomenon was probably derived from the increasing of driving force for $\mathrm{Ce}$ (III) mass transfer and electrolyte conductivity while increasing initial Ce(III) concentration. When the initial $\mathrm{Ce}(\mathrm{III})$ concentration was increased, the Ce(IV) 


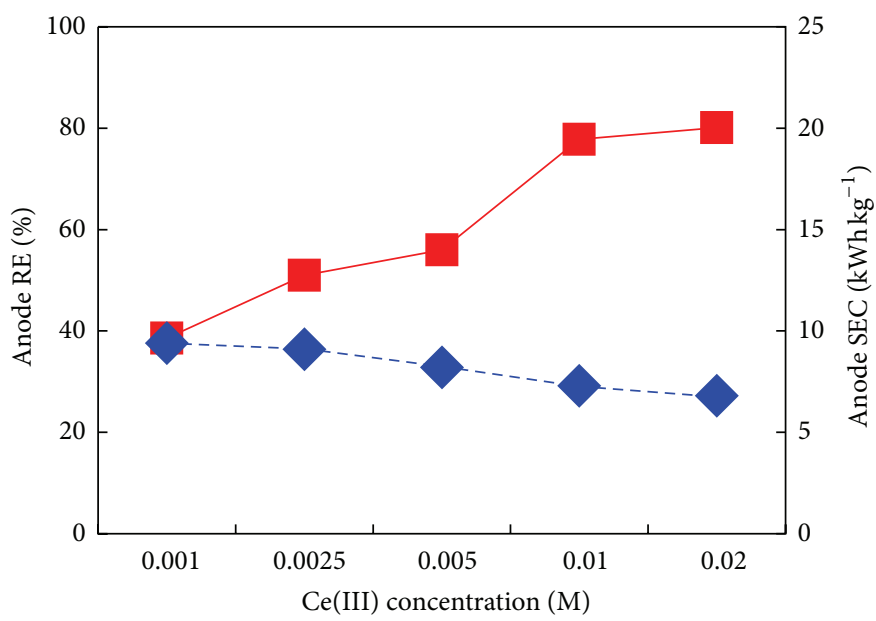

(a)

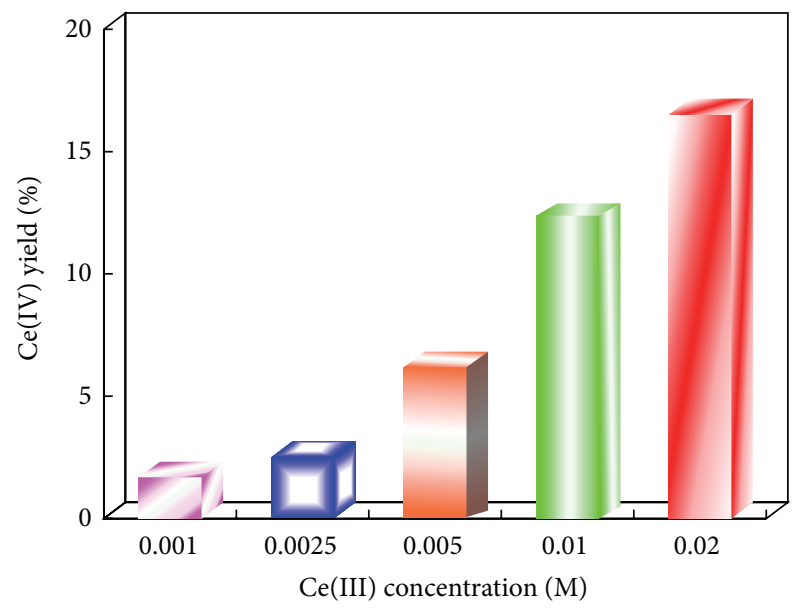

(b)

FIgURE 3: Effect of initial Ce(III) concentration: (a) removal efficiency and SEC of PVA and (b) Ce(IV) yield with different initial Ce(III) concentration in the anodic compartment (current density $=3 \mathrm{~mA} \mathrm{~cm}^{-2}$, temperature $=323 \mathrm{~K}$, anodic compartment: $\mathrm{PVA}_{3}=50 \mathrm{mg} \mathrm{L} \mathrm{L}^{-1}, \mathrm{HNO}_{3}$ $=0.2 \mathrm{M}$; cathodic compartment: $\mathrm{PVA}=50 \mathrm{mg} \mathrm{L}^{-1}, \mathrm{Na}_{2} \mathrm{SO}_{4}=0.05 \mathrm{M}, \mathrm{pH}=3$, oxygen flow rate $=500 \mathrm{~cm}^{3} \mathrm{~min}^{-1}$, and UV-light intensity = $0.4 \mathrm{~mW} \mathrm{~cm}^{-2}$ ).

ion concentration also increased, as shown in Figure 3(b). However, if the initial Ce(III) concentration was higher than $0.01 \mathrm{M}$, the PVA removal efficiency did not increase significantly.

In order to evaluate the effect of initial Ce(III) concentration on the specific energy consumption and PVA removal efficiency, a number of experiments were performed after $120 \mathrm{~min}$ of electrolysis while keeping the current density, solution temperature, and anodic supporting electrolyte at $3 \mathrm{~mA} \mathrm{~cm}^{-2}, 323 \mathrm{~K}$, and $0.2 \mathrm{M} \mathrm{HNO}_{3}$ in the anodic compartment; oxygen flow rate, UV light intensity, and cathodic supporting electrolyte at $500 \mathrm{~cm}^{3} \mathrm{~min}^{-1}, 0.4 \mathrm{~mW} \mathrm{~cm}^{-2}$, and $0.05 \mathrm{M} \mathrm{Na}_{2} \mathrm{SO}_{4}$ in the cathodic compartment. Figure 3(b) also shows the effect of the initial Ce(III) concentration on the SEC during the paired photoelectrochemical oxidative system. As shown in the figure, the SEC decreased from $9.4 \mathrm{kWh} \mathrm{kg}^{-1}$ to $6.8 \mathrm{kWh} \mathrm{kg}^{-1}$ when the initial Ce(IV) concentration increased from 0.001 to $0.02 \mathrm{M}$. Although there was a significant downward trend for the SEC while the initial Ce(III) concentration increased, the SEC was not significantly changed by increasing $\mathrm{Ce}$ (III) ion concentration from 0.01 to $0.02 \mathrm{M}$. Consequently, the initial Ce(III) concentration of $0.01 \mathrm{M}$ provides the optimum performance for this system; it provides a reasonable PVA removal efficiency and a relatively low electrical energy consumption.

3.2.2. Effect of Nitric Acid Concentration. Electrochemical treatments need salts or acid for supporting the electrolytes that make the solution more conductive. In comparison with low solubility of sulfuric acid on the cerium, nitric acid is often chosen in the past references [20, 29, 36]. Therefore, nitric acid was used as the anodic supporting electrolyte to increase the solution conductivity and thus reduce the SEC in the present study. In order to decrease environmental pollutions, we used a comparatively lower acid concentration in this study. The effect on the PVA removal efficiency of varying the nitric acid from 0.1 to $0.5 \mathrm{M}$ was studied, as shown in Figure 4(a). It was observed that the removal efficiency increased as the concentration of nitric acid was increased in the anodic compartment. After $120 \mathrm{~min}$ of electrolysis, $40.8 \%, 77.8 \%, 80.1 \%, 82.2 \%$, and $83.5 \%$ of the original PVA were removed at nitric acid concentrations of $0.1,0.2,0.3,0.4$, and $0.5 \mathrm{M}$, respectively. Nitric acid is a strong oxidant and in favor of the generation of $\mathrm{Ce}(\mathrm{IV})$. Figure 4 (b) also indicated that $\mathrm{Ce}(\mathrm{IV})$ yield increased with increasing nitric acid concentration. As the Ce(IV) yield increased, the PVA removal efficiency also increased. However, if the concentration of nitric acid was higher than $0.3 \mathrm{M}$, the PVA removal efficiency did not increase significantly.

The concentration of the supporting electrolyte was adjusted by adding a suitable amount of nitric acid to the anodic compartment. Figure 4(a) also indicates the effect of the nitric acid concentration on the PVA removal efficiency and SEC during the paired photoelectrochemical oxidative system. Figure 4(a) also indicates that SEC decreased from $13.1 \mathrm{kWh} \mathrm{kg}^{-1}$ to $5.4 \mathrm{kWh} \mathrm{kg}^{-1}$ when the concentration of the nitric acid increased from 0.1 to $0.5 \mathrm{M}$. It was observed that the SEC was significantly decreased almost $60 \%$. Although there was a significant downward trend for the SEC when the nitric acid concentration increased, the SEC did not significantly vary by increasing acid concentration from 0.3 to $0.5 \mathrm{M}$. Consequently, $0.3 \mathrm{M}$ nitric acid concentration provided the optimum balance between the removal efficiency at the specific energy consumption. 


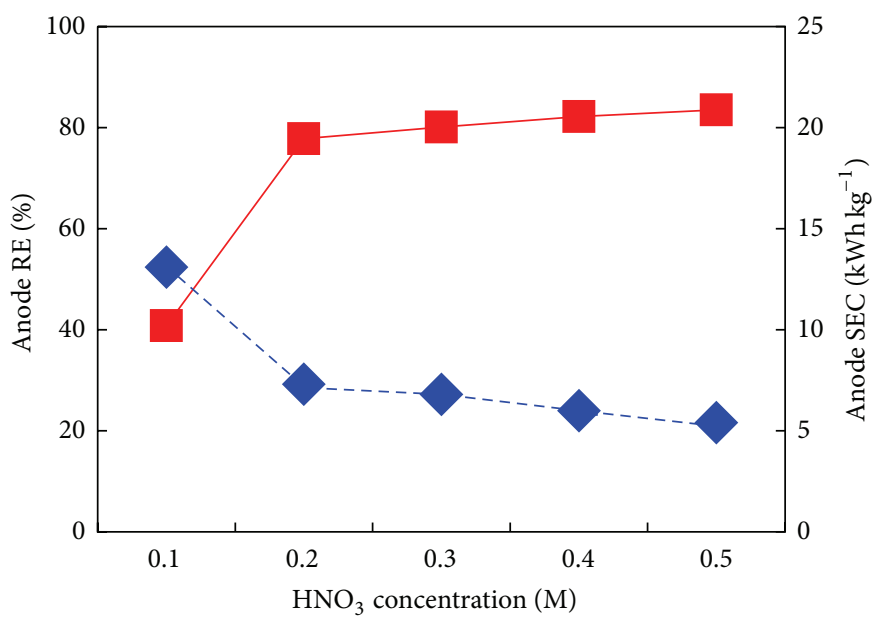

Anode RE

Anode SEC

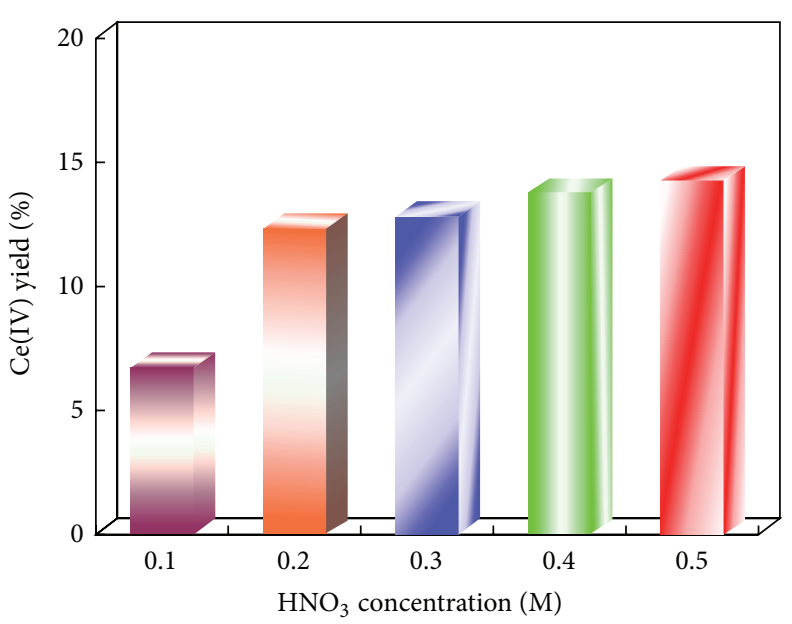

(b)

FIGURE 4: Effect of $\mathrm{HNO}_{3}$ concentration: (a) removal efficiency and SEC of PVA and (b) Ce(IV) yield with different $\mathrm{HNO}_{3}$ concentration in the anodic compartment (current density $=3 \mathrm{~mA} \mathrm{~cm}^{-2}$, temperature $=323 \mathrm{~K}$, anodic compartment: $\mathrm{PVA}=50 \mathrm{mg} \mathrm{L}-1, \mathrm{Ce}(\mathrm{III})=0.01 \mathrm{M}$; cathodic compartment: $\mathrm{PVA}=50 \mathrm{mg} \mathrm{L}^{-1}, \mathrm{Na}_{2} \mathrm{SO}_{4}=0.05 \mathrm{M}, \mathrm{pH}=3$, oxygen flow rate $=500 \mathrm{~cm}^{3} \mathrm{~min}^{-1}$, and UV-light intensity $=0.4 \mathrm{~mW} \mathrm{~cm}^{-2}$ ).

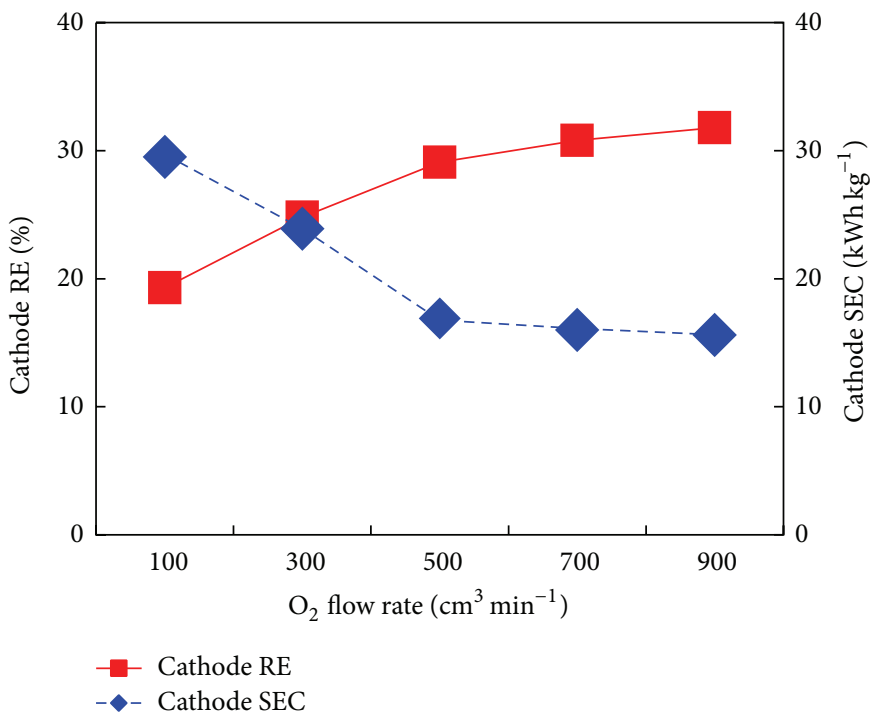

(a)

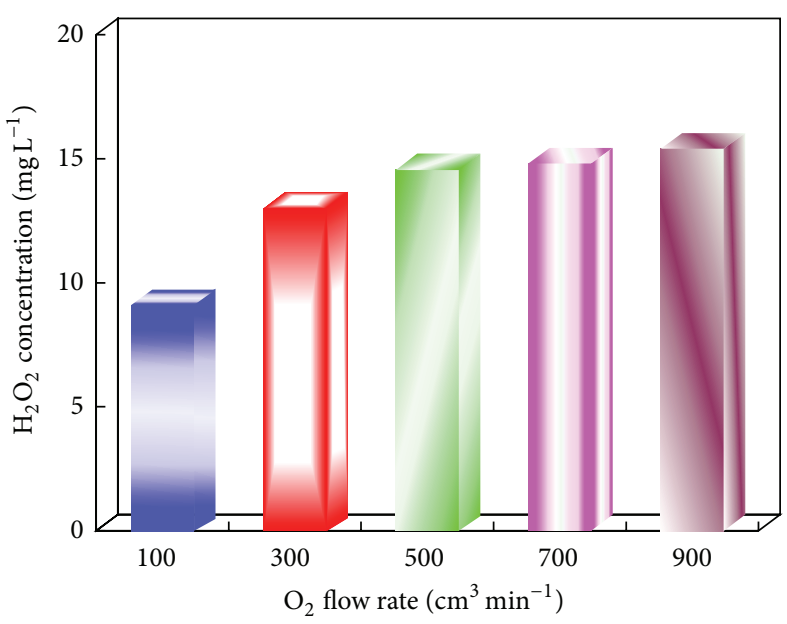

(b)

FIGURE 5: Effect of oxygen flow rate: (a) removal efficiency and SEC of PVA and (b) concentration of $\mathrm{H}_{2} \mathrm{O}_{2}$ generation with different oxygen flow rate in the cathodic compartment (current density $=3 \mathrm{~mA} \mathrm{~cm}^{-2}$, temperature $=323 \mathrm{~K}$, anodic compartment: $\mathrm{PVA}=50 \mathrm{mg} \mathrm{L}{ }^{-1}, \mathrm{Ce}(\mathrm{III})$ $=0.01 \mathrm{M}, \mathrm{HNO}_{3}=0.3 \mathrm{M}$; cathodic compartment: $\mathrm{PVA}=50 \mathrm{mg} \mathrm{L}^{-1}, \mathrm{Na}_{2} \mathrm{SO}_{4}=0.05 \mathrm{M}, \mathrm{pH}=3$, and UV-light intensity $=0.4 \mathrm{~mW} \mathrm{~cm}^{-2}$ ).

\subsection{Removal of PVA in the Cathodic Compartment}

3.3.1. Effect of Oxygen Flow Rate. In this study, the yield of $\mathrm{H}_{2} \mathrm{O}_{2}$ electrogeneration via oxygen reduction at the cathode significantly affects the PVA removal efficiency of cathodic compartment. The effect of the oxygen flow rate on the PVA removal efficiency was studied at 100 to $900 \mathrm{~cm}^{3} \mathrm{~min}^{-1}$, as shown in Figure 5(a). For increased oxygen flow rate, significant increases in the PVA removal efficiency were observed, suggesting that the increase of the oxygen flow rate improves PVA removal rate. After 120 min of electrolysis, while the oxygen flow rate increased from 100, 300, 500, 700, and $900 \mathrm{~cm}^{3} \mathrm{~min}^{-1}$, the concentration of PVA was removed significantly, increasing from 19.3, 24.8, 29.1, 30.8, and 31.8\%, respectively. This reason was that when the oxygen flow rate was increased, the concentration of dissolved oxygen and mass transfer rate of dissolved oxygen were increased, thereby accelerating the electrogeneration of $\mathrm{H}_{2} \mathrm{O}_{2}$ which 


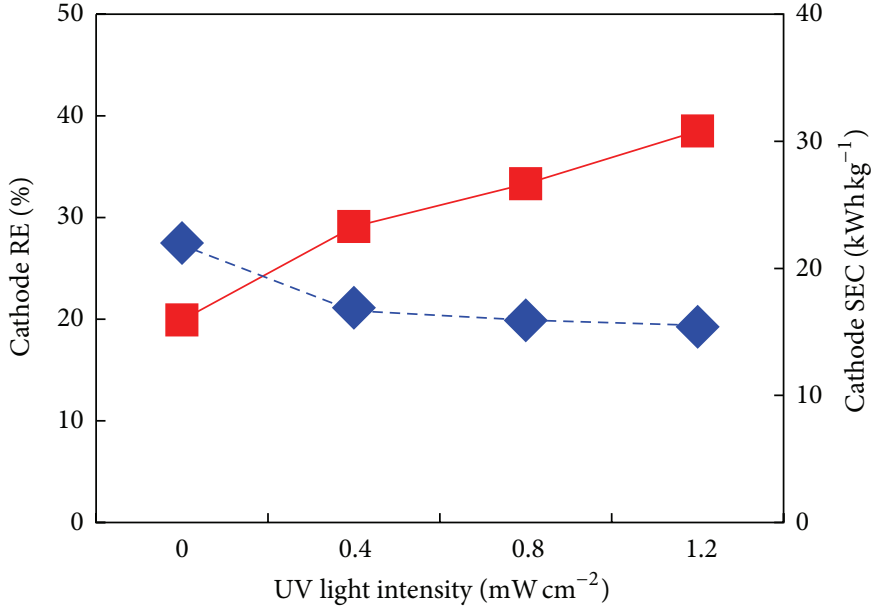

(a)

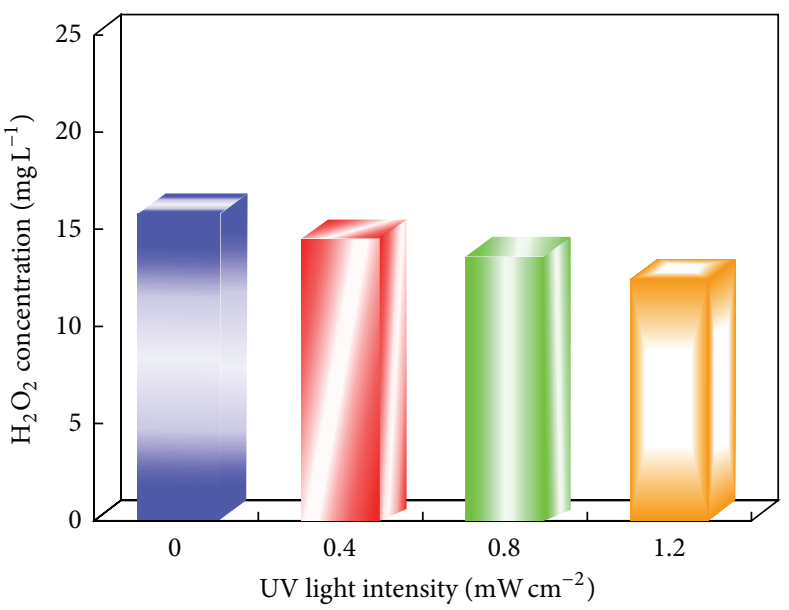

(b)

FIGURE 6: Effect of UV-light intensity: (a) removal efficiency and SEC of PVA and (b) concentration of $\mathrm{H}_{2} \mathrm{O}_{2}$ generation with different UVlight intensity in the cathodic compartment (current density $=3 \mathrm{~mA} \mathrm{~cm}^{-2}$, temperature $=323 \mathrm{~K}$, anodic compartment: $\mathrm{PVA}=50 \mathrm{mg} \mathrm{L} \mathrm{L}^{-1}$, $\mathrm{Ce}(\mathrm{III})=0.01 \mathrm{M}, \mathrm{HNO}_{3}=0.3 \mathrm{M}$; cathodic compartment: $\mathrm{PVA}=50 \mathrm{mg} \mathrm{L}^{-1}, \mathrm{Na}_{2} \mathrm{SO}_{4}=0.05 \mathrm{M}, \mathrm{pH}=3$, and oxygen flow rate $=500 \mathrm{~cm}^{3} \mathrm{~min}^{-1}$ ).

was dissociated into more hydroxyl radicals. Therefore, the hydroxyl radicals can oxidize PVA to improve removal efficiency. Figure 5(b) demonstrated that the electrogeneration of $\mathrm{H}_{2} \mathrm{O}_{2}$ increased with increasing of the oxygen flow rate. However, above an oxygen flow rate of $500 \mathrm{~cm}^{3} \mathrm{~min}^{-1}$, the oxygen and $\mathrm{H}_{2} \mathrm{O}_{2}$ concentration followed a steady trend. The results illustrated that the saturated solubility of oxygen in aqueous solutions was nearly accomplished at the oxygen flow rate of $500 \mathrm{~cm}^{3} \mathrm{~min}^{-1}$ [37]. To investigate the optimum oxygen flow rate, the performance of the specific energy consumption at a certain oxygen flow rate during this system was evaluated; these results were given in the following section.

PVA solutions were treated using paired photoelectrochemical oxidative system at oxygen flow rates in the range of 100 to $900 \mathrm{~cm}^{3} \mathrm{~min}^{-1}$ to determine the optimal removal efficiency and specific energy consumption. The effect of the oxygen flow rate on removal efficiency and specific energy consumption was shown in Figure 5(a). The specific energy consumption decreased significantly by approximately $50 \%$, when the oxygen flow rate was increased from 100 to $900 \mathrm{~cm}^{3} \mathrm{~min}^{-1}$, whereas the corresponding PVA removal efficiency in the cathodic compartment increased from $19.3 \%$ to $31.8 \%$. However, when the oxygen flow rate was increased from 500 to 700 and $900 \mathrm{~cm}^{3} \mathrm{~min}^{-1}$, the specific energy consumption decreased slightly from 16.9 to 16 and $15.6 \mathrm{kWh} \mathrm{kg}^{-1}$, respectively, whereas the corresponding PVA removal efficiency in the cathodic compartment increased from $29.1 \%$ to $31.8 \%$, respectively. Consequently, on consideration of the removal efficiency and specific energy consumption values for PVA removal in the cathodic compartment, an oxygen flow rate of $500 \mathrm{~cm}^{3} \mathrm{~min}^{-1}$ offers the best performance with reasonable removal efficiency and relatively low specific energy consumption.
3.3.2. Effect of UV Irradiation Intensity. The UV irradiation intensity is an important factor that strongly controls the concentration of hydroxyl radicals generated. In this study, the effect of the UV light intensity on PVA removal efficiency and SEC was investigated at $0,0.4,0.8$, and $1.2 \mathrm{~mW} \mathrm{~cm}^{-2}$, as shown in Figure 6(a). After 120 min of electrolysis, it was observed that the maximum PVA removal efficiency was found at $1.2 \mathrm{~mW} \mathrm{~cm}^{-2}$. The PVA removal efficiency reached $19.9 \%, 29.1 \%, 33.3 \%$, and $38.5 \%$ for UV light intensities of $0,0.4,0.8$, and $1.2 \mathrm{~mW} \mathrm{~cm}^{-2}$, respectively. It appears that increasing UV light intensity increases the PVA removal efficiency. This experimental results explained that higher UV light intensity can improve the generation of hydroxyl radicals to remove PVA from the solution $[22,23]$. On the one hand, the rate of photolysis of hydrogen was limited at lower UV light intensity, resulted in decreased PVA removal efficiency. Figure 6(b) shows the concentration of hydrogen peroxide generation at various UV light intensities. As shown in Figure 6(b), after $120 \mathrm{~min}$ of electrolysis, $15.8 \%, 14.5 \%$, $13.6 \%$, and $12.4 \%$ of the hydrogen peroxide was generated for UV light intensities of $0,0.4,0.8$, and $1.2 \mathrm{~mW} \mathrm{~cm}^{-2}$, respectively. It is clear that increasing the UV light intensity can effectively increase the generation of hydroxyl radicals, result in the hydrogen peroxide decreased. Therefore, at a higher UV light intensity the amount of hydroxyl radicals generation in the reaction cell was found well.

Figure 6(a) also shows the effect of UV light intensity on the PVA removal efficiency and specific energy consumption after $120 \mathrm{~min}$ of electrolysis by paired photoelectrochemical oxidative system. The SEC values decreased from $22 \mathrm{kWh} \mathrm{kg}^{-1}$ to $15.4 \mathrm{kWh} \mathrm{kg}^{-1}$ when the UV light intensities were increased from 0 to $1.2 \mathrm{~mW} \mathrm{~cm}^{-2}$, whereas the corresponding PVA removal efficiency increased significantly from $19.9 \%$ to $38.5 \%$. Consequently, when considering both 
the SEC values and the PVA removal efficiency in the cathodic compartment, a UV light intensity of $1.2 \mathrm{~mW} \mathrm{~cm}^{-2}$ offers the best overall performance with a reasonable PVA removal efficiency and relatively low SEC values.

\section{Conclusions}

Electrooxidation of $\mathrm{Ce}(\mathrm{III})$ in nitric acid medium for the anodic MEO process and electrogeneration of $\mathrm{H}_{2} \mathrm{O}_{2}$ in acid medium for the cathodic PEO process were performed using the divided electrochemical cell fabricated in our study. The removal efficiency of PVA tin aqueous solutions via this innovative paired photo-electrochemical oxidative system was investigated in anodic compartment and cathodic compartment conditions, respectively. Various operating parameters such as the current density, the initial Ce(III) concentration, nitric acid concentration, oxygen flow rate, and UV irradiation intensity were investigated in this study. The yield of the $\mathrm{Ce}(\mathrm{IV})$ concentration and $\mathrm{H}_{2} \mathrm{O}_{2}$ on the different operational parameters by MEO process of the anodic compartment and PEO process of the cathodic compartment were also calculated. The current density of $3 \mathrm{~mA} \mathrm{~cm}^{-2}$ was regarded as optimum for a reasonable PVA removal efficiency with a relatively low specific energy consumption. Considering the removal efficiency and SEC, an initial Ce(III) concentration of $0.1 \mathrm{M}$, nitric acid concentration of $0.3 \mathrm{M}$, oxygen flow rate of $500 \mathrm{~cm}^{3} \mathrm{~min}^{-1}$, and UV irradiation of $1.2 \mathrm{~mW} \mathrm{~cm} \mathrm{~cm}^{-2}$ were found be the optimum values for the present study. The results indicate that an innovative paired photoelectrochemical oxidative system, combining anodic MEO process and cathodic PEO process, would be regarded as a potential alternative to remove PVA in aqueous solutions.

\section{Conflict of Interests}

The authors declare that there is no conflict of interests with any financial organization regarding the material discussed in this study.

\section{Acknowledgments}

The authors would like to thank the National Science Council of Taiwan, ROC, for financially supporting this study under contract no. NSC101-2628-E-241-013-MY3.

\section{References}

[1] X.-Y. Pang, "Adsorption characteristics of polyvinyl alcohols in solution on expanded graphite," E-Journal of Chemistry, vol. 9, no. 1, pp. 240-252, 2012.

[2] J. B. Chang, J. H. Hwang, J. S. Park, and J. P. Kim, “The effect of dye structure on the dyeing and optical properties of dichroic dyes for PVA polarizing film," Dyes and Pigments, vol. 88, no. 3 , pp. 366-371, 2011.

[3] J. A. Giroto, R. Guardani, A. C. S. C. Teixeira, and C. A. O. Nascimento, "Study on the photo-Fenton degradation of polyvinyl alcohol in aqueous solution," Chemical Engineering and Processing, vol. 45, no. 7, pp. 523-532, 2006.
[4] K. Yoo, Sequential biological treatment including ozonation for persistent organic compounds [Ph.D. thesis], Korea Advanced Institute of Science and Technology, Daejeon, South Korea, 1999.

[5] J. G. Lim and D. H. Park, "Degradation of polyvinyl alcohol by Brevibacillus laterosporus: metabolic pathway of polyvinyl alcohol to acetate," Journal of Microbiology and Biotechnology, vol. 11, no. 6, pp. 928-933, 2001.

[6] A. K. Bajpai and N. Vishwakarma, "Adsorption of polyvinylalcohol onto Fuller's earth surfaces," Colloids and Surfaces A: Physicochemical and Engineering Aspects, vol. 220, no. 1-3, pp. 117-130, 2003.

[7] S. K. Behera, J.-H. Kim, X. Guo, and H.-S. Park, "Adsorption equilibrium and kinetics of polyvinyl alcohol from aqueous solution on powdered activated carbon," Journal of Hazardous Materials, vol. 153, no. 3, pp. 1207-1214, 2008.

[8] Y. Chen, Z. Sun, Y. Yang, and Q. Ke, "Heterogeneous photocatalytic oxidation of polyvinyl alcohol in water," Journal of Photochemistry and Photobiology A: Chemistry, vol. 142, no. 1, pp. 85-89, 2001.

[9] L.-J. Hsu, L.-T. Lee, and C.-C. Lin, "Adsorption and photocatalytic degradation of polyvinyl alcohol in aqueous solutions using P-25 $\mathrm{TiO}_{2}$," Chemical Engineering Journal, vol. 173, no. 3, pp. 698-705, 2011.

[10] C.-C. Lin, L.-T. Lee, and L.-J. Hsu, "Performance of $\mathrm{UV} / \mathrm{S}_{2} \mathrm{O}_{8}{ }^{2-}$ process in degrading polyvinyl alcohol in aqueous solutions," Journal of Photochemistry and Photobiology A: Chemistry, vol. 252, no. 1, pp. 1-7, 2013.

[11] K.-Y. Huang, C.-T. Wang, W.-L. Chou, and C.-M. Shu, "Removal of polyvinyl alcohol using photoelectrochemical oxidation processes based on hydrogen peroxide electrogeneration," International Journal of Photoenergy, vol. 2013, Article ID 841762, 9 pages, 2013.

[12] A. M. T. Silva, R. N. P. Vaz, R. M. Quinta-Ferreira, and J. Levec, "Gas-liquid-solid reactions of polyvinyl alcohol on oxidation treatments for environmental pollution remediation," The Canadian Journal of Chemical Engineering, vol. 81, no. 3-4, pp. 566-573, 2003.

[13] S. Kim, T.-H. Kim, C. Park, and E.-B. Shin, "Electrochemical oxidation of polyvinyl alcohol using a RuO2/Ti anode," Desalination, vol. 155, no. 1, pp. 49-57, 2003.

[14] W.-L. Chou, C.-T. Wang, C.-W. Hsu, K.-Y. Huang, and T.-C. Liu, "Removal of total organic carbon from aqueous solution containing polyvinyl alcohol by electrocoagulation technology," Desalination, vol. 259, no. 1-3, pp. 103-110, 2010.

[15] W.-L. Chou, L.-S. Chen, C.-T. Wang, and S.-R. Lee, "Electrofenton removal of polyvinyl alcohol from aqueous solutions using an activated carbon fiber cathode," Fresenius Environmental Bulletin, vol. 21, no. 12, pp. 3735-3742, 2012.

[16] X. Chen and G. Chen, "Anodic oxidation of orange II on Ti/BDD electrode: variable effects," Separation and Purification Technology, vol. 48, no. 1, pp. 45-49, 2006.

[17] S. Ammar, R. Abdelhedi, C. Flox, C. Arias, and E. Brillas, "Electrochemical degradation of the dye indigo carmine at boron-doped diamond anode for wastewaters remediation," Environmental Chemistry Letters, vol. 4, no. 4, pp. 229-233, 2006.

[18] C.-T. Wang, J.-L. Hu, W.-L. Chou, and Y.-M. Kuo, "Removal of color from real dyeing wastewater by Electro-Fenton technology using a three-dimensional graphite cathode," Journal of Hazardous Materials, vol. 152, no. 2, pp. 601-606, 2008. 
[19] E. Neyens and J. Baeyens, "A review of classic Fenton's peroxidation as an advanced oxidation technique," Journal of Hazardous Materials, vol. 98, no. 1-3, pp. 33-50, 2003.

[20] S. Balaji, S. J. Chung, R. Thiruvenkatachari, and I. S. Moon, "Mediated electrochemical oxidation process: electro-oxidation of cerium(III) to cerium(IV) in nitric acid medium and a study on phenol degradation by cerium(IV) oxidant," Chemical Engineering Journal, vol. 126, no. 1, pp. 51-57, 2007.

[21] A. R. Khataee, V. Vatanpour, and A. R. Amani Ghadim, "Decolorization of C.I. Acid Blue 9 solution by UV/Nano$\mathrm{TiO}_{2}$, Fenton, Fenton-like, electro-Fenton and electrocoagulation processes: a comparative study," Journal of Hazardous Materials, vol. 161, no. 2-3, pp. 1225-1233, 2009.

[22] M. Muruganandham and M. Swaminathan, "Photochemical oxidation of reactive azo dye with $\mathrm{UV}-\mathrm{H}_{2} \mathrm{O}_{2}$ process," Dyes and Pigments, vol. 62, no. 3, pp. 269-275, 2004.

[23] N. Modirshahla and M. A. Behnajady, "Photooxidative degradation of Malachite Green (MG) by $\mathrm{UV} / \mathrm{H}_{2} \mathrm{O}_{2}$ : influence of operational parameters and kinetic modeling," Dyes and Pigments, vol. 70, no. 1, pp. 54-59, 2006.

[24] M. A. Fard, B. Aminzadeh, M. Taheri, S. Farhadi, and M. Maghsoodi, "MBR excess sludge reduction by combination of electrocoagulation and Fenton oxidation processes," Separation and Purification Technology, vol. 120, no. 1, pp. 378-385, 2013.

[25] C. Zhou, N. Gao, Y. Deng, W. Chu, W. Rong, and S. Zhou, "Factors affecting ultraviolet irradiation/hydrogen peroxide $\left(\mathrm{UV} / \mathrm{H}_{2} \mathrm{O}_{2}\right)$ degradation of mixed $\mathrm{N}$-nitrosamines in water," Journal of Hazardous Materials, vol. 231-232, no. 1, pp. 43-48, 2012.

[26] X. He, M. Pelaez, J. A. Westrick et al., "Efficient removal of microcystin-LR by UV-C/ $\mathrm{H}_{2} \mathrm{O}_{2}$ in synthetic and natural water samples," Water Research, vol. 46, no. 5, pp. 1501-1510, 2012.

[27] J. C. Farmer, F. T. Wang, P. R. Lewis, and L. J. Summers, "Destruction of chlorinated organics by cobalt(III)-mediated electrochemical oxidation," Journal of the Electrochemical Society, vol. 139, no. 11, pp. 3025-3029, 1992.

[28] V. V. Kokovkin, S. J. Chung, S. Balaji, M. Matheswaran, and I.S. Moon, "Electrochemical cell current requirements for toxic organic waste destruction in Ce(IV)-mediated electrochemical oxidation process," Korean Journal of Chemical Engineering, vol. 24, no. 5, pp. 749-756, 2007.

[29] S. Balaji, S. J. Chung, M. Matheswaran, K. V. Vasilivich, and I. S. Moon, "Destruction of organic pollutants by cerium(IV) MEO process: a study on the influence of process conditions for EDTA mineralization," Journal of Hazardous Materials, vol. 150, no. 3, pp. 596-603, 2008.

[30] S. J. Chung, K. Chandrasekara Pillai, and I. S. Moon, "A sustainable environmentally friendly $N O_{x}$ removal process using Ag(II)/Ag(I)-mediated electrochemical oxidation," Separation and Purification Technology, vol. 65, no. 2, pp. 156-163, 2009.

[31] M. Sudoh, H. Kitaguchi, and K. Koide, "Electrochemical production of hydrogen peroxide by reduction of oxygen," Journal of Chemical Engineering of Japan, vol. 18, no. 5, pp. 409-414, 1985.

[32] Y. Wei, B. Fang, T. Arai, and M. Kumagai, "Electrolytic oxidation of $\mathrm{Ce}$ (III) in nitric acid and sulfuric acid media using a flow type cell," Journal of Applied Electrochemistry, vol. 35, no. 6, pp. 561566, 2005.

[33] T. Raju and C. A. Basha, "Electrochemical cell design and development for mediated electrochemical oxidation Ce (III)/ Ce (IV) system," Chemical Engineering Journal, vol. 114, no. 1-3, pp. 55-65, 2005.
[34] J. H. Finley, "Spectrophotometric determination of polyvinyl alcohol in paper coatings," Analytical Chemistry, vol. 33, no. 13, pp. 1925-1927, 1961.

[35] W. L. Chou, C. T. Wang, and K. Y. Huang, "Investigation of process parameters for the removal of polyvinyl alcohol from aqueous solution by iron electrocoagulation," Desalination, vol. 251, no. 1-3, pp. 12-19, 2010.

[36] K.-L. Huang, T.-S. Chen, and K.-J. C. Yeh, "Regeneration of $\mathrm{Ce}(\mathrm{IV})$ in simulated spent Cr-etching solutions using an undivided cell," Journal of Hazardous Materials, vol. 171, no. 1-3, pp. 755-760, 2009.

[37] A. Özcan, Y. Şahin, A. S. Koparal, and M. A. Oturan, "Carbon sponge as a new cathode material for the electro-Fenton process: comparison with carbon felt cathode and application to degradation of synthetic dye basic blue 3 in aqueous medium," Journal of Electroanalytical Chemistry, vol. 616, no. 1-2, pp. 7178,2008 . 

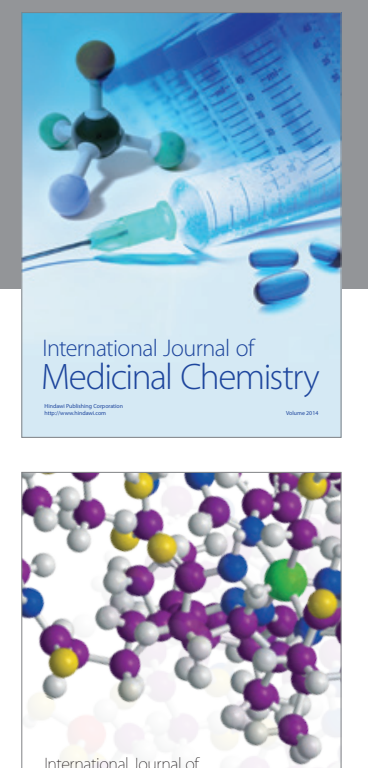

\section{Carbohydrate} Chemistry

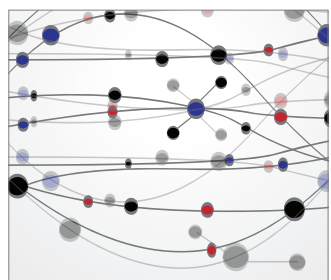

The Scientific World Journal
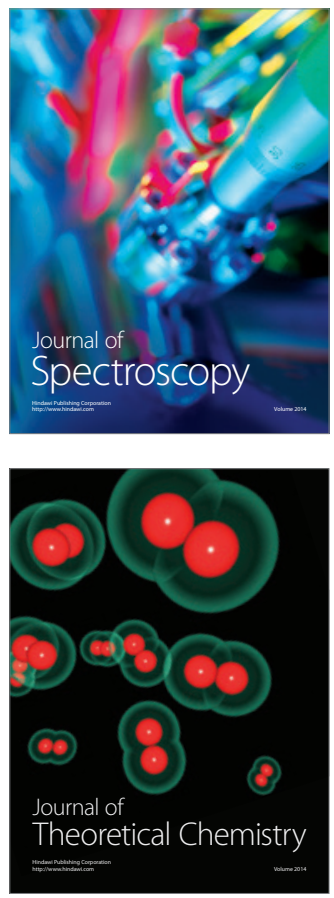
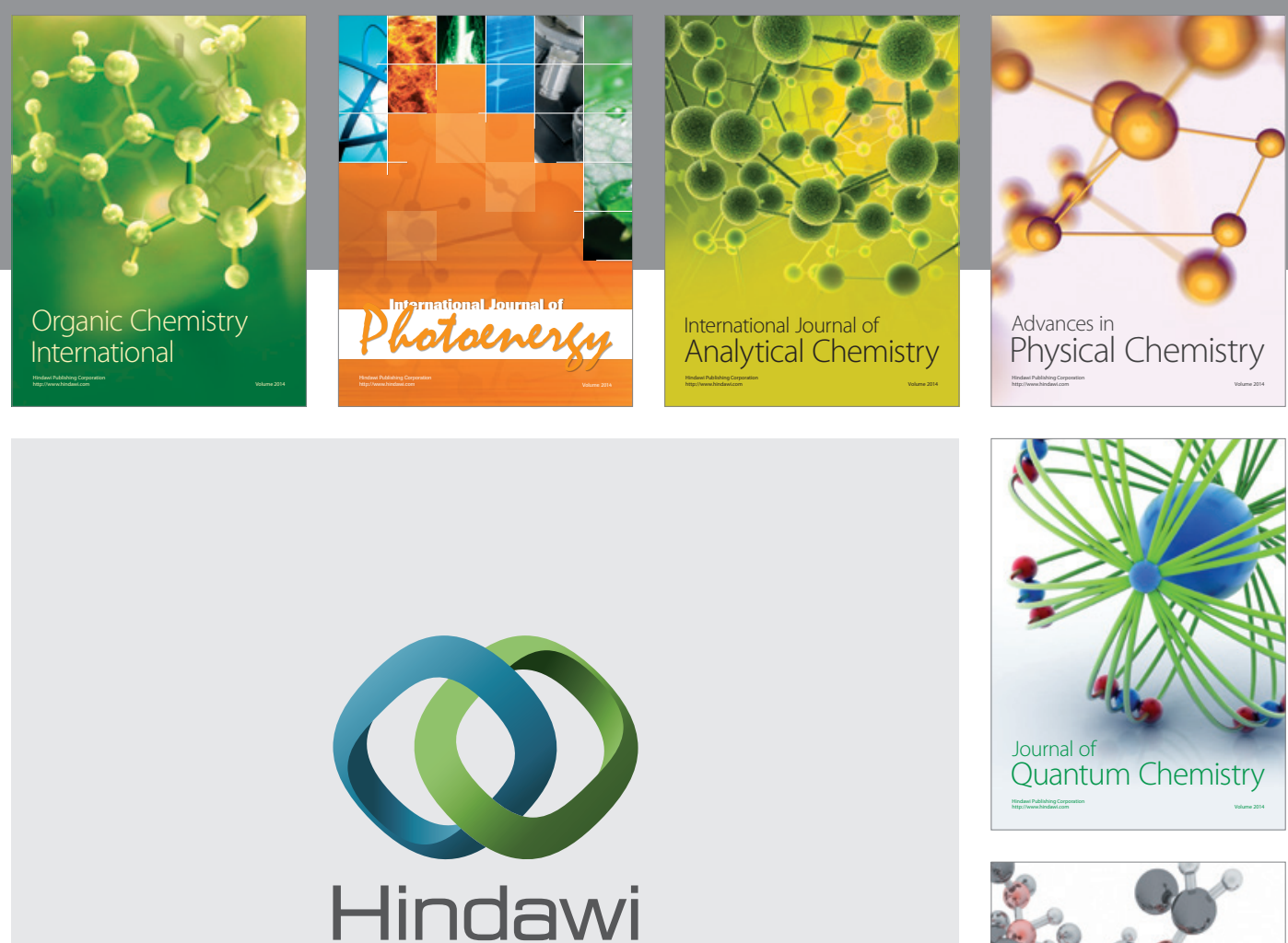

Submit your manuscripts at

http://www.hindawi.com

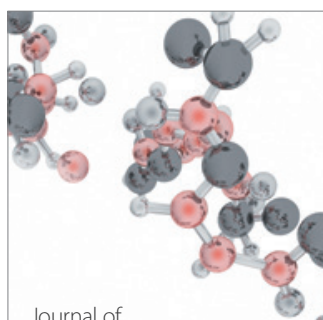

Analytical Methods

in Chemistry

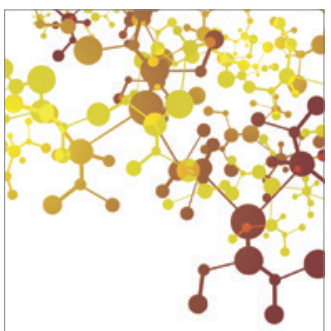

Journal of

Applied Chemistry

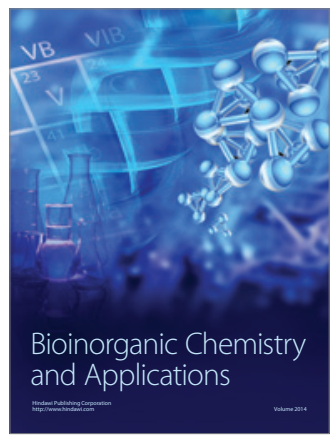

Inorganic Chemistry
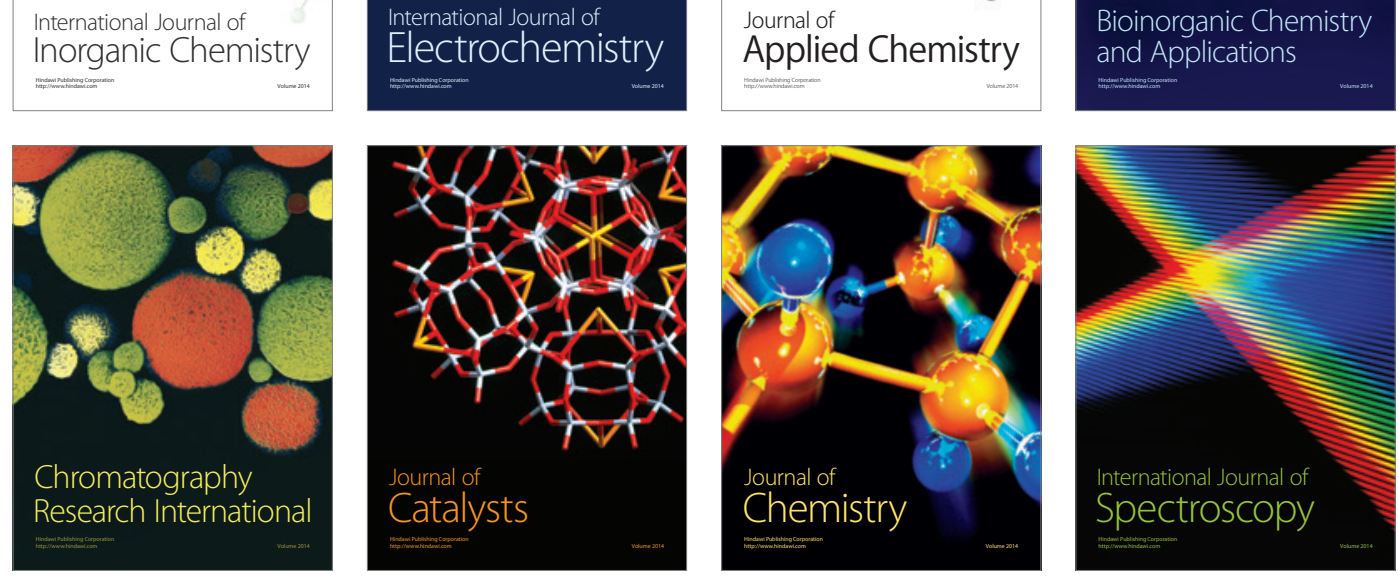